\title{
Study of the optical response of phase-change recording layer with zinc oxide nanostructured thin film
}

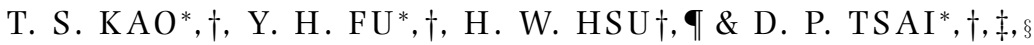 \\ *Department of Physics, National Taiwan University, Taipei 10617, Taiwan \\ †Center for Nanostorage Research, National Taiwan University, Taipei 10617, Taiwan \\ $\ddagger$ Institute of Electro-optical Science and Technology, National Taiwan Normal University, Taipei \\ 11677, Taiwan \\ $\S R e s e a r c h$ Center for Applied Sciences, Academia Sinica, Taipei 115, Taiwan \\ IDepartment of Physics, National Central University, Jung-Li, 32054, Taiwan
}

Key words. Near-field optical disk, phase-change recording material, ultra-high density recording, $\mathrm{ZnO}_{x}$ nanostructured thin film.

\begin{abstract}
Summary
Recently, use of nanostructured materials as a near-field optical active layer has attracted a lot of interest. The non-linear optical properties and strong enhancements of metallic oxide nanostructured thin films are key functions in applications of promising nanophotonics. For the importance of ultra-high density optical data storage, we continue investigating the ultra-high density recording property of near-field optical disk consisting of zinc oxide $\left(\mathrm{ZnO}_{x}\right)$ nanostructured thin film. A carrier-to-noise ratio above $38 \mathrm{~dB}$ at a recording mark size of $100 \mathrm{~nm}$ can be obtained in the $\mathrm{ZnO}_{x}$ near-field optical disk by a DVD driver tester directly. In this article, we use an optical pump-probe system (static media tester) to measure the optical response of a phase-change recording layer $\left(\mathrm{Ge}_{2} \mathrm{Sb}_{2} \mathrm{Te}_{5}\right)$ and demonstrate the high contrast of optical recording with a $\mathrm{ZnO}_{x}$ nanostructured thin film in short pulse durations. Also, we investigate the dependence of writing power and the optical response in conventional re-writable recording layers and the phase-change material with $\mathrm{ZnO}_{x}$ nanostructured thin film.
\end{abstract}

\section{Introduction}

A wide band gap of $3.37 \mathrm{eV}$ and a large excitonic binding energy of $60 \mathrm{meV}$ have made zinc oxide $(\mathrm{ZnO})$ a promising photonic material for developing short-wavelength optical devices (Bagnall et al., 1997). Nanostructured ZnO has attracted manifold interest recently for its room-temperature blue-UV lasing and wide optoelectronic applications (Cao, Xu,

Correspondence to: Din Ping Tsai. Tel: +886-2-33665100; fax: +886-2-23639928; e-mail: dptsai@phys.ntu.edu.tw

Present address: Department of Physics, National Taiwan University, 1, Sec. 4, Roosevelt Road, Taipei 10617, Taiwan, R.O.C.
Seelig, et al., 2000; Cao, Xu, Zhang, et al., 2000; Wiersma, 2000; Huang et al., 2001). To pursue ultra-high density optical recording ability, a promising method that uses a metallic oxide nanostructured thin film as a near-field optical active layer to promote and enhance signals between adjacent recording marks has been studied in several types of near-field optical disks with metallic oxide nanostructured thin films (Tsai \& Lin, 2000; Tsai et al., 2000; Liu et al., 2001; Yu et al., 2004; Fu et al., 2006). To achieve our purpose of ultra-high density recording ability, we prepare sputtered $\mathrm{ZnO}_{x}$ nanostructured thin film as a near-field optical active layer to attain ultra-high density recording. A carrier-to-noise ratio (CNR) above $38 \mathrm{~dB}$ at the recording mark size of $100 \mathrm{~nm}$ can be measured by a conventional DVD driver tester (DDU-1000, Pulstec) with a wavelength of incident laser of $658 \mathrm{~nm}(\lambda)$ (Lin et al., 2003). The read-out signals of $\mathrm{ZnO}_{x}$-type near-field optical disk and the nanostructure of a $\mathrm{ZnO}_{x}$ nanostructured thin film are studied as well. To investigate the optical properties of $\mathrm{ZnO}_{x}$ nanostructured thin film and its potential applications, we use an optical pump-probe system (static media tester, Toptica) to investigate the optical responses of a phase-change material $\left(\mathrm{Ge}_{2} \mathrm{Sb}_{2} \mathrm{Te}_{5}\right)$ with sandwiched $\mathrm{ZnO}_{x}$ nanostructured thin film, and the results are compared with that of conventional rewritable recording layers.

\section{Materials and methods}

Preparation of $\mathrm{ZnO}_{\mathrm{x}}$ nanostructured thin-film samples with different layered structure

$\mathrm{ZnO}_{x}$ nanostructured thin film is prepared by the RFmagnetron reactive sputtering method. Pure Zn (purity: $4 \mathrm{~N}$, diameter: $76 \mathrm{~mm}$ ) is used as a target, and gas flows of Ar and 


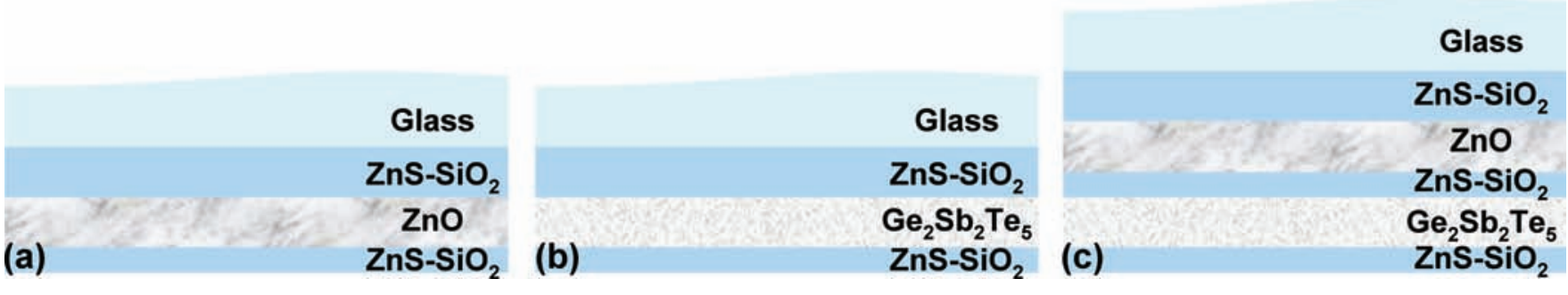

Fig. 1. The scheme of prepared samples with different layered structures. (a) Sandwiched $\mathrm{ZnO}_{x}$ nanostructured thin film: glass $\backslash \mathrm{ZnS}^{-} \mathrm{SiO}_{2} \backslash \mathrm{ZnO}_{x} \backslash$ $\mathrm{ZnS}-\mathrm{SiO}_{2}$; (b) conventional recording layered structure: glass $\backslash \mathrm{ZnS}-\mathrm{SiO}_{2} \backslash \mathrm{Ge}_{2} \mathrm{Sb}_{2} \mathrm{Te}_{5} \backslash \mathrm{ZnS}-\mathrm{SiO}_{2}$; (c) $\mathrm{ZnO}_{x}$-type near-field optical disk structure: glass $\backslash \mathrm{ZnS}-\mathrm{SiO}_{2} \backslash \mathrm{ZnO}_{x} \backslash \mathrm{ZnS}-\mathrm{SiO}_{2} \backslash \mathrm{Ge}_{2} \mathrm{Sb}_{2} \mathrm{Te}_{5} \backslash \mathrm{ZnS}-\mathrm{SiO}_{2}$.

$\mathrm{O}_{2}$ are precisely regulated, respectively. The thickness of $\mathrm{ZnO}_{x}$ nanostructured thin film can be precisely controlled by the sputtering rate $\left(1.38 \mathrm{~A} \mathrm{~s}^{-1}\right.$ for $\mathrm{ZnO}_{x}$ ) and time. Sputtering power and pressure are fixed at $200 \mathrm{~W}$ and $0.5 \mathrm{~Pa}$. As showed in Fig. 1, the layered structures that we studied are sandwiched $\mathrm{ZnO}_{x}$ nanostructured thin film, cover glass $\backslash \mathrm{ZnS}-\mathrm{SiO}_{2}(130$

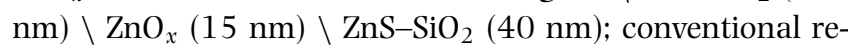
writable recording layer, cover glass $\backslash \mathrm{ZnS}-\mathrm{SiO}_{2}(130 \mathrm{~nm}) \backslash$ $\mathrm{Ge}_{2} \mathrm{Sb}_{2} \mathrm{Te}_{5}(20 \mathrm{~nm}) \backslash \mathrm{ZnS}-\mathrm{SiO}_{2}(20 \mathrm{~nm})$ and $\mathrm{ZnO}{ }_{x}$-type nearfield optical disk structure, that is, phase-change recording layer with $\mathrm{ZnO}_{x}$ nanostructured thin film, cover glass $\backslash \mathrm{ZnS}-$ $\mathrm{SiO}_{2}(130 \mathrm{~nm}) \backslash \mathrm{ZnO}_{x}(15 \mathrm{~nm}) \backslash \mathrm{ZnS}-\mathrm{SiO}_{2}(40 \mathrm{~nm}) \backslash$ $\mathrm{Ge}_{2} \mathrm{Sb}_{2} \mathrm{Te}_{5}(20 \mathrm{~nm}) \backslash \mathrm{ZnS}-\mathrm{SiO}_{2}(20 \mathrm{~nm})$.

\section{Optical pump-probe system (static media tester)}

After the preparation of $\mathrm{ZnO}_{x}$ nanostructured thin film with different layered structure, we use an optical pump-probe system (static media tester, Toptica) to measure the optical response on a phase-change recording layer $\left(\mathrm{Ge}_{2} \mathrm{Sb}_{2} \mathrm{Te}_{5}\right)$. The scheme of the experimental set-up is shown in Fig. 2. The wavelength of pulse laser for writing is $658 \mathrm{~nm}$ and that of CW laser for reading is $633 \mathrm{~nm}$. The writing power is changed from 1 to $20 \mathrm{~mW}$ and the reading power is fixed at $0.6 \mathrm{~mW}$. The writing laser power and pulse duration are controlled during the recording process. The time evaluated reflectance signal of writing laser and reading laser from the sample are monitored simultaneously. The CCD camera with an objective lens (N.A. $=0.6,40 \times)$ can be used to observe the structural change and reflectance variation on the surface of irradiated phase-change recording layer.

\section{Results and discussion}

Figure 3 shows the TEM image (cross-section, Fig. 3(a)) and electron diffraction pattern (Fig. 3(b)) of the sandwiched zinc oxide $\left(\mathrm{ZnO}_{x}\right)$ nanostructured thin film (JEM-4000EX HR-TEM, JEOL). The layered structure of $\mathrm{ZnO}_{x}$ nanostructured thin film is silicon $\backslash \mathrm{ZnS}-\mathrm{SiO}_{2}(130 \mathrm{~nm}) \backslash \mathrm{ZnO}_{x}(15 \mathrm{~nm}) \backslash \mathrm{ZnS}-\mathrm{SiO}_{2}$ $(40 \mathrm{~nm})$. In Fig. 3(a), the $\mathrm{ZnO}_{x}$ nanostructured thin film looks like nanoteeth sandwiched by two dielectric thin films (ZnS$\mathrm{SiO}_{2}$ ). The diameter of the $\mathrm{ZnO}_{x}$ nanotooth is about $8 \mathrm{~nm}$ and its growing direction is about $12-13^{\circ}$ deviated from the normal. This interesting property reported by Huang and coworkers (Cao, Xu, Seelig, et al., 2000; Cao, Xu, Zhang et al., 2000) may imply that the novelty of the nanowire or nanorod could be applied to the $\mathrm{ZnO}_{x}$ nanostructured thin film of $\mathrm{ZnO}_{x}$-type near-field optical disk (Chu et al., 2005, 2007). Thus, it is suggested that the ensemble effects of these $\mathrm{ZnO}_{x}$ nanostructures are the key factors for induction of the ultrahigh density recording ability observed in our study. Fig. 3(b) shows the electron diffraction pattern of the sandwiched $\mathrm{ZnO}_{x}$ nanostructured thin film. It indicates that the orientation of crystalline $\mathrm{ZnO}_{x}$ nanoteeth is (101) (Pan et al., 2001; JCPDS file 36-1451).

Figure 4 shows the $\mathrm{CCD}$ image and reflectance variation of sandwiched $\mathrm{ZnO}_{x}$ nanostructured thin film with different incident pulse power (both including writing and reading power). The pulse power is changed from 1 to $20 \mathrm{~mW}$ and the pulse duration is fixed at $50 \mu \mathrm{s}$. In the results of CCD image and reflectance variation, no matter how much higher is the pulse power applied, the appearance of CCD image and the variation of optical reflectance remain the same. The invariability of appearance and reflectance indicates that there is no heat accumulation or destruction on sandwiched $\mathrm{ZnO}_{x}$ nanostructured thin film. Moreover, the pulse power of 20 $\mathrm{mW}$ and the pulse duration of $50 \mu \mathrm{s}$ are much higher and longer than the conventional writing strategy on optical disks. It means that the $\mathrm{ZnO}_{x}$ nanostructured thin film is a thermal stable material using in ultra-high density recording (Pan et al., 2001).

In the comparison of optical response of conventional rewritable recording layered structure and the phase-change material $\left(\mathrm{Ge}_{2} \mathrm{Sb}_{2} \mathrm{Te}_{5}\right)$ with $\mathrm{ZnO}_{x}$ nanostructured thin film, we intend to investigate the optical variation on the phase-change recording layer with different writing power $(1-20 \mathrm{~mW})$ and pulse duration (50-1000 ns). In the results of short pulse duration $(t=50 \mathrm{~ns})$, Fig. 5 shows the CCD images of conventional re-writable recording layer and $\mathrm{ZnO}_{x}$-type near-field optical disk structure, respectively. In Fig. 5(a), the CCD image of conventional re-writable recording layer shows that there is no obvious recording mark produced in such a short pulse duration. However, in Fig. 5(b), the recording 


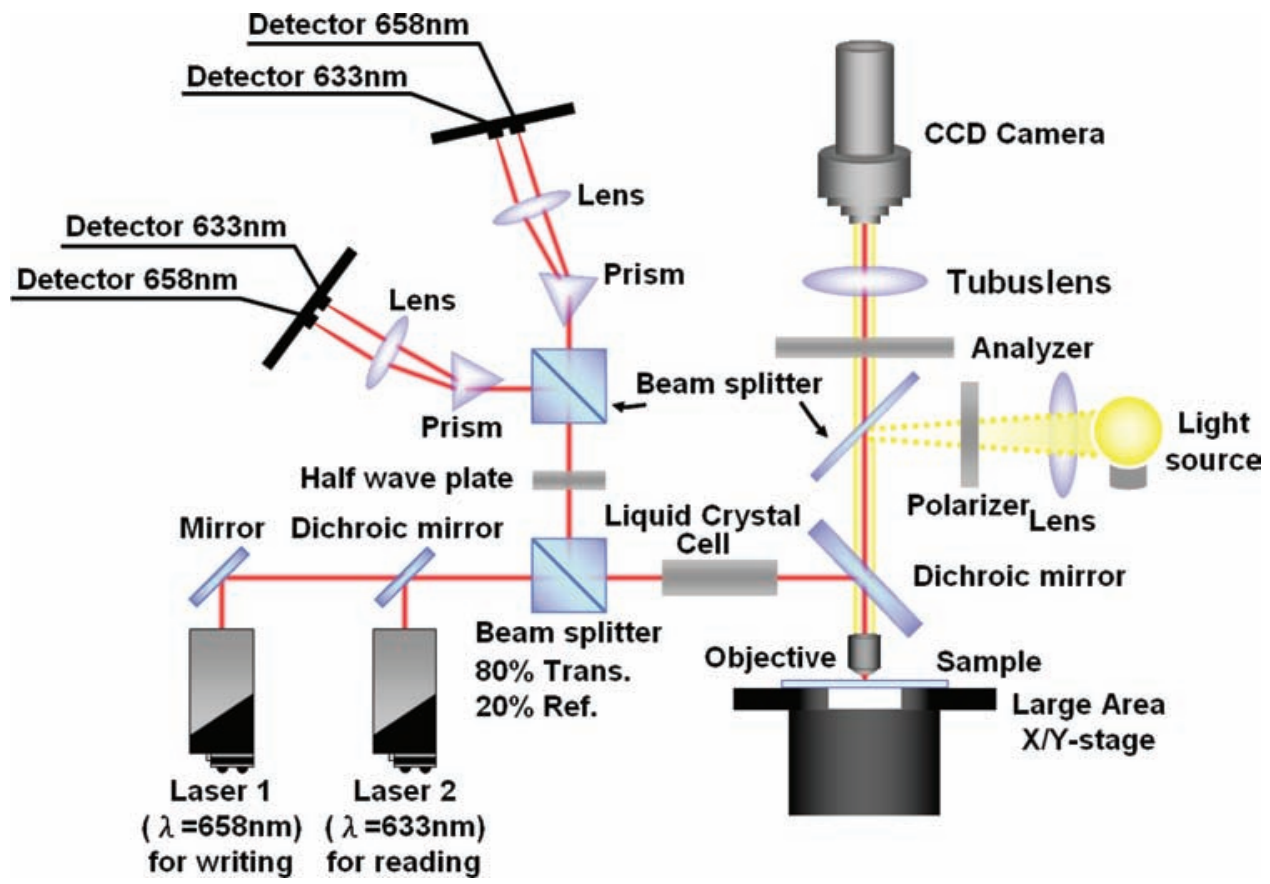

Fig. 2. The experimental set-up of an optical pump-probe system (static media tester, Toptica).

marks can be observed and the contrast of recording mark can be increased with a $\mathrm{ZnO}_{x}$ nanostructured thin film. The $\mathrm{ZnO}_{x}$ nanostructured thin film not only shortens the time of phase-change recording mark formation but also promotes the contrast of read-out ability.

Figs 6 and 7 show the CCD images and the reflectance of recording marks on conventional re-writable recording layered structure $\left(\mathrm{Ge}_{2} \mathrm{Sb}_{2} \mathrm{Te}_{5}\right)$ and the phase-change material with $\mathrm{ZnO}_{x}$ nanostructured thin film, respectively. The writing power is changed from 1 to $20 \mathrm{~mW}$ and the pulse duration is fixed at 200 ns. Figure 6(b) shows the reflectance variation in pulse duration with writing and reading power. The contrast $\Delta$ denotes the difference of optical reflectance of reading power before and after incident pulse laser irradiation. During the irradiation of incident pulse laser, the optical reflectance of higher writing power $(>15 \mathrm{~mW})$ decreases step by step and the contrast $\Delta$ increases with writing power. The occurrence of decreasing reflectance of writing power corresponds to the CCD image as showed in Fig. 6(a). As the phase-change recording layer $\left(\mathrm{Ge}_{2} \mathrm{Sb}_{2} \mathrm{Te}_{5}\right)$ is an optical and heat-based material (Miyamoto et al., 1998; Ohta et al., 2000; Kooi et al., 2004; Lin et al., 2006;), it is obvious that the decreasing reflectance of writing power comes from the structural change of destroyed hole on the surface of phase-change recording layer. The diameter of destroyed hole depends on the power of incident pulse laser (20 mW, $1.464 \mu \mathrm{m} ; 15 \mathrm{~mW}, 1.440 \mu \mathrm{m})$. The increasing diameter of destroyed hole gives the evidence of increasing contrast with increasing incident pulse power. In the comparison of optical response of phase-change material with $\mathrm{ZnO}_{x}$ nanostructured thin film (Fig. 7), the contrast is more distinguishable than that of the conventional rewritable recording layer at the same power of incident pulse

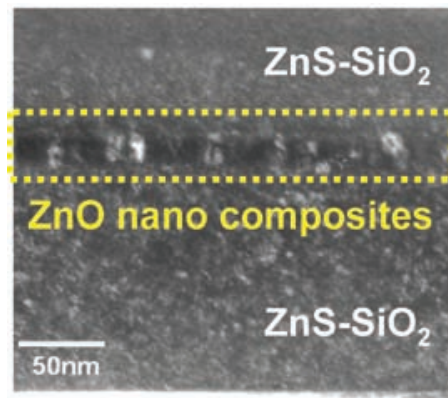

(a) TEM image (cross section)

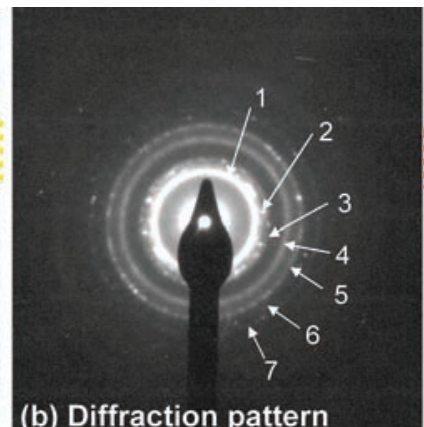

1. $0.304 \mathrm{~nm}$

2. $0.261 \mathrm{~nm}(002)$ 3. $0.247 \mathrm{~nm}$ (101) 4. $0.185 \mathrm{~nm}$

5. $0.162 \mathrm{~nm}(110)$

6. $0.146 \mathrm{~nm}(103)$

7. $0.134 \mathrm{~nm}$ (201)

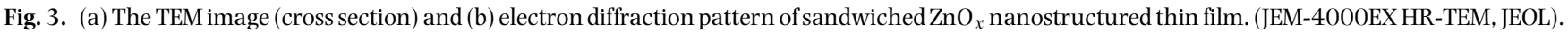




\section{Glass $\backslash \mathrm{ZnS}-\mathrm{SiO}_{2}(130 \mathrm{~nm}) \backslash \mathrm{ZnO}_{\mathrm{x}}(15 \mathrm{~nm}) \backslash \mathrm{ZnS}-\mathrm{SiO}_{2}(40 \mathrm{~nm})$}

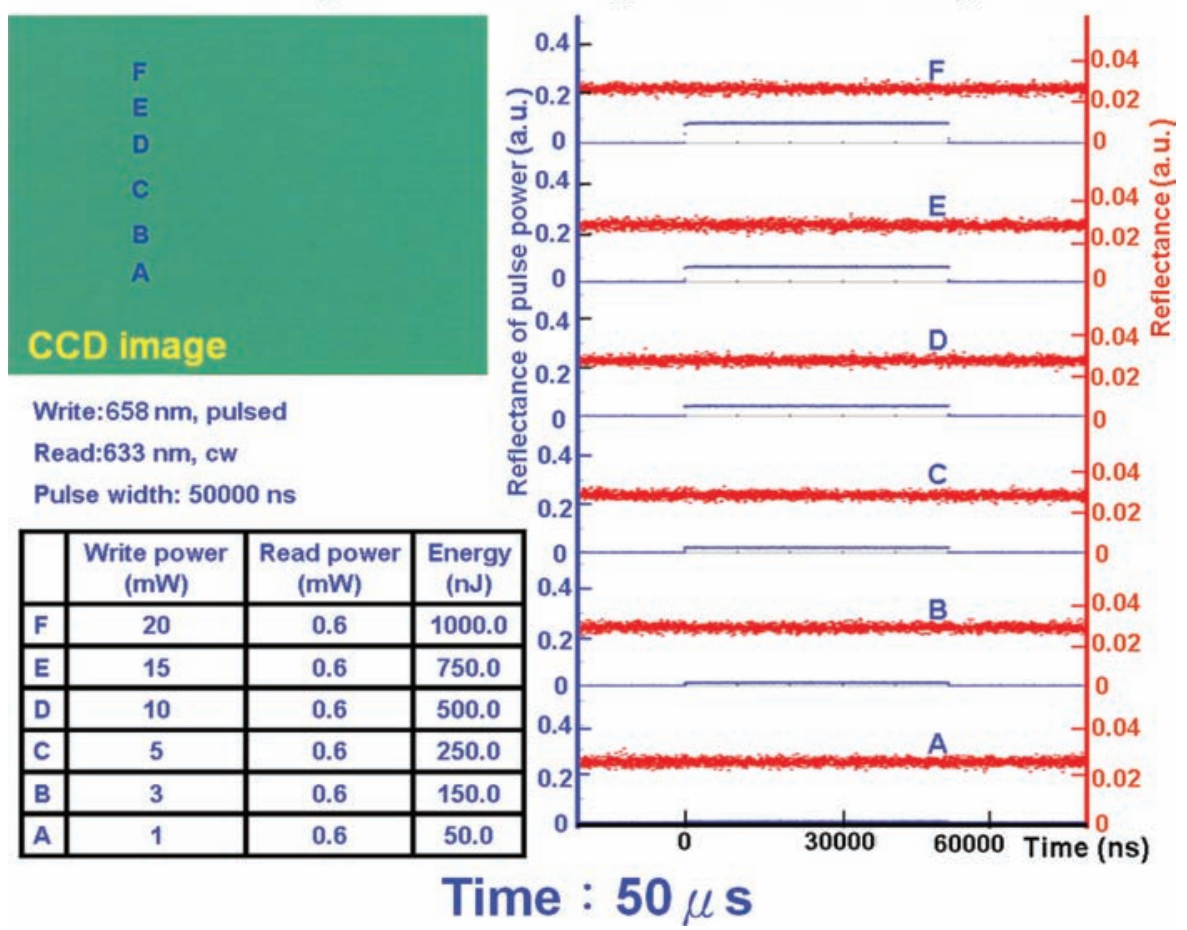

Fig. 4. The optical response of sandwiched $\mathrm{ZnO}_{x}$ nanostructured thin film. The power of pulse laser is changed from 1 to $20 \mathrm{~mW}$ and the pulse duration is $50 \mu \mathrm{s}$.

laser and also increases with incident writing power. The higher contrast shows the reflectance promotion of the $\mathrm{ZnO}_{x}$ nanostructured thin film. In the higher writing power $(>15$ $\mathrm{mW}$ ), the reflectance of writing power also decreases step by step. However, in Fig. 7(a), the CCD image of the recording mark shows structural change of destroyed hole, with a tiny bright spot produced at the centre on the surface of the phasechange recording layer. The diameter of the destroyed hole and that of the tiny bright spot both depend on the writing power (destroyed hole: $20 \mathrm{~mW}, 1.545 \mu \mathrm{m} ; 15 \mathrm{~mW}, 1.486 \mu \mathrm{m}$; tiny bright spot: $20 \mathrm{~mW}, 0.759 \mu \mathrm{m} ; 15 \mathrm{~mW}, 0.750 \mu \mathrm{m})$. Because the sandwiched $\mathrm{ZnO}_{x}$ nanostructured thin film is independent from the power of incident pulse laser and pulse duration (as the results of Fig. 4), there is no heat accumulation or structural change on sandwiched $\mathrm{ZnO}_{x}$ nanostructured thin film. The tiny bright spots are produced at the phase-change recording material $\left(\mathrm{Ge}_{2} \mathrm{Sb}_{2} \mathrm{Te}_{5}\right)$ with the $\mathrm{ZnO}_{x}$ nanostructured thin film.

Figure 8 shows the comparison of the reflectance contrast with different applied pulse writing power on a conventional re-writable layered structure and the phase-change material with $\mathrm{ZnO}_{x}$ nanostructured thin film. The pulse writing power is changed from 1to $20 \mathrm{~mW}$ and the pulse duration is
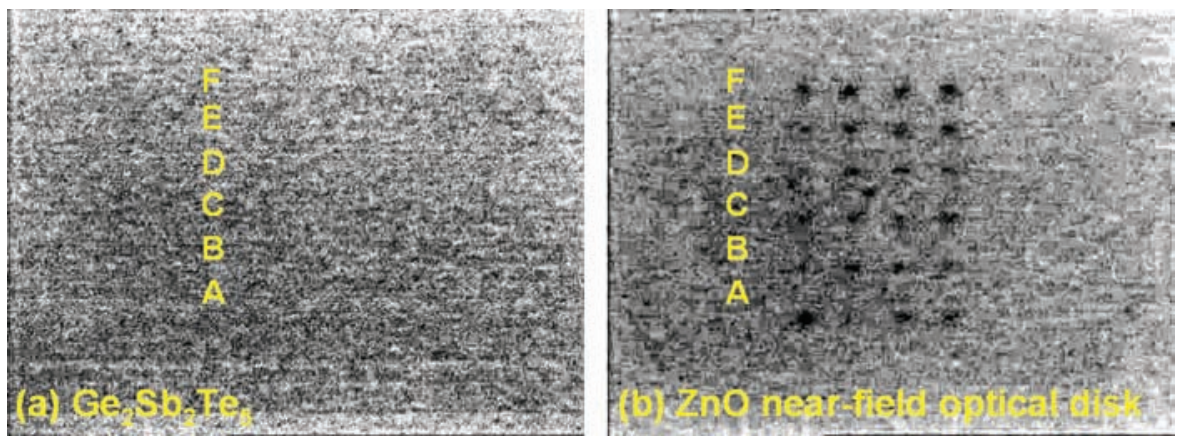

Fig. 5. The comparison of CCD images with different layered structure. (a) Conventional re-writable recording layered structure: glass $\backslash \mathrm{ZnS}-\mathrm{SiO}{ }_{2}$ (130 $\mathrm{nm}) \backslash \mathrm{Ge}_{2} \mathrm{Sb}_{2} \mathrm{Te}_{5}(20 \mathrm{~nm}) \backslash \mathrm{ZnS}-\mathrm{SiO}_{2}(20 \mathrm{~nm})$; (b) $\mathrm{ZnO}_{x}$-type near-field optical disk structure: glass $\backslash \mathrm{ZnS}^{-\mathrm{SiO}_{2}}(130 \mathrm{~nm}) \backslash \mathrm{ZnO}{ }_{x}(15 \mathrm{~nm}) \backslash \mathrm{ZnS}-\mathrm{SiO}_{2}$ $(40 \mathrm{~nm}) \backslash \mathrm{Ge}_{2} \mathrm{Sb}_{2} \mathrm{Te}_{5}(20 \mathrm{~nm}) \backslash \mathrm{ZnS}-\mathrm{SiO}_{2}(20 \mathrm{~nm})$. The power of pulse laser is changed from 1 to $20 \mathrm{~mW}$ and the pulse duration is $50 \mathrm{~ns}$. 
(a) CCD image

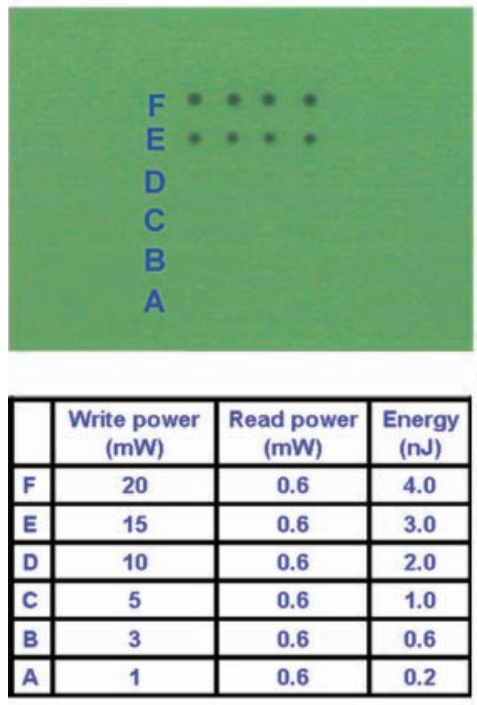

(b) Time dependent reflectance

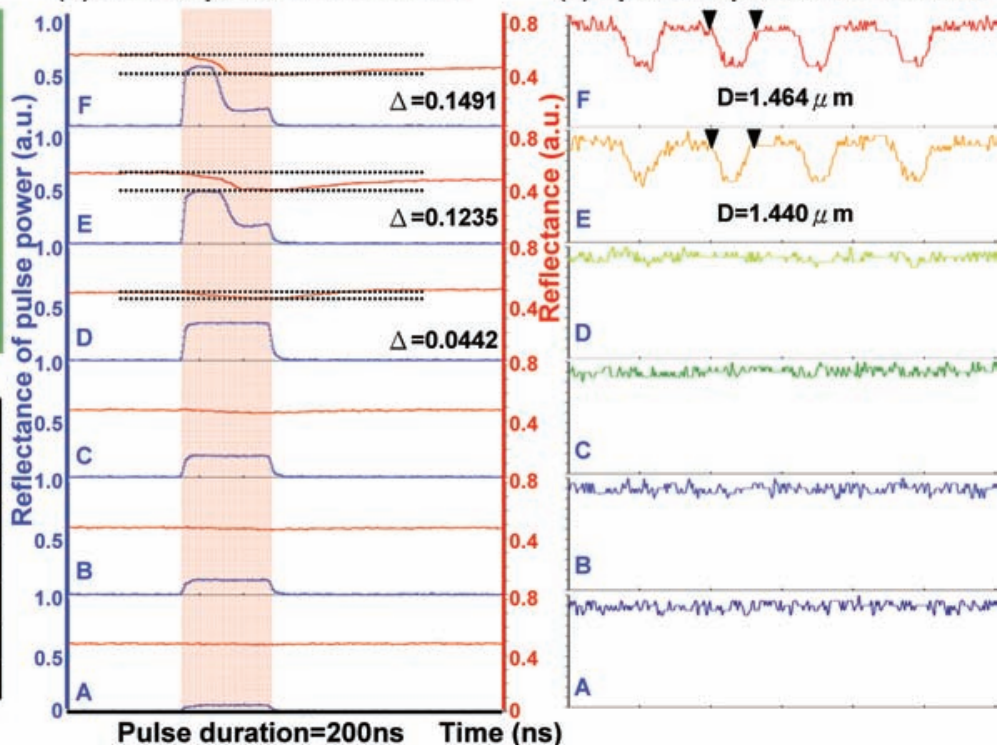

Fig. 6. The optical response of conventional re-writable recording layered structure in a pulse duration of $200 \mathrm{~ns}$.

\section{(a) CCD image}

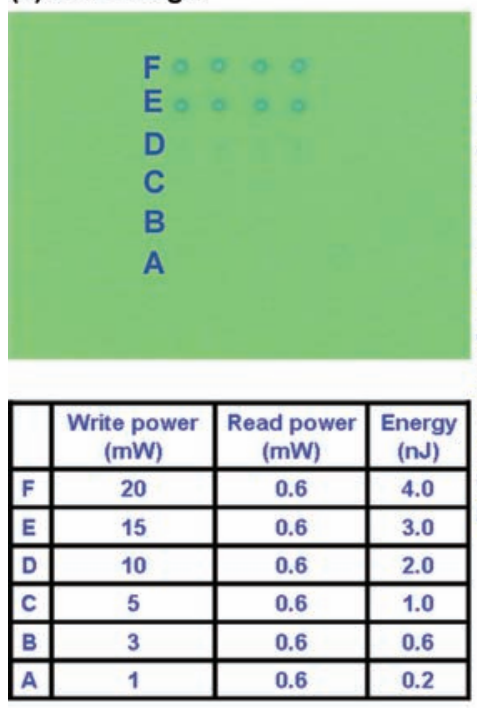

(b) Time dependent reflectance

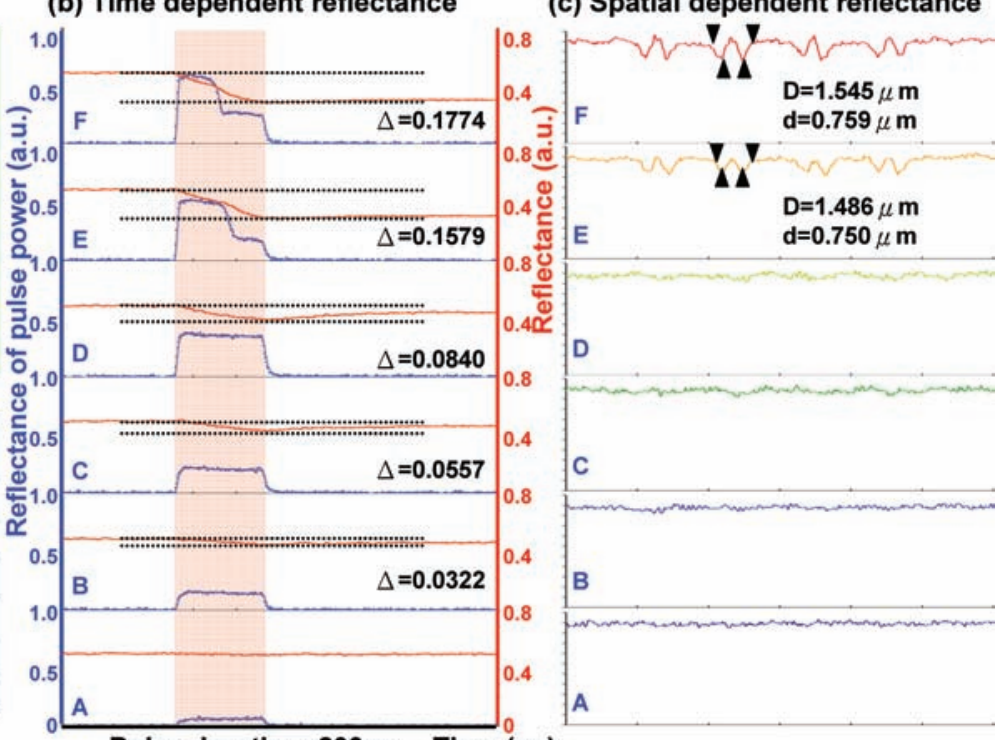

Pulse duration=200ns Time (ns) (c) Spatial dependent reflectance

Fig. 7. The optical response of $\mathrm{ZnO}_{x}$-type near-field optical disk structure in a pulse duration of $200 \mathrm{~ns}$.

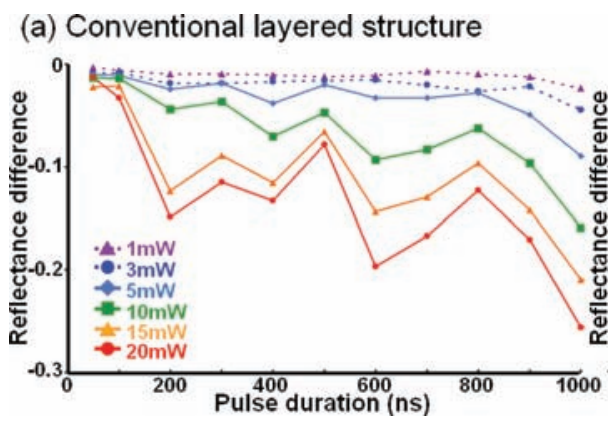

(b) ZnO near-field optical disk

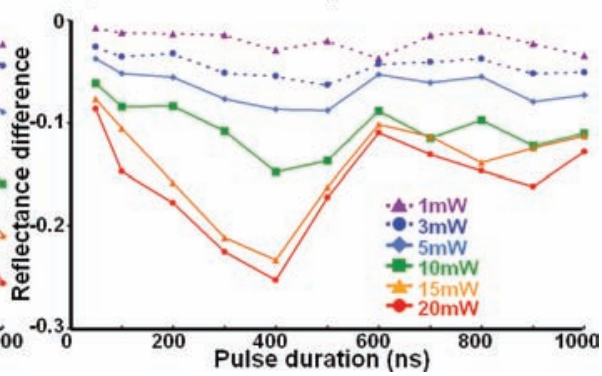

Fig. 8. The comparison of the highest contrast in different pulse durations with different layered structures. (a) conventional re-writable recording layered structure and (b) $\mathrm{ZnO}_{x}$-type near-field optical disk structure. 
changed from 50 to 1000 ns. In Fig. 8(a), the reflectance contrast depends on the pulse duration and the pulse writing power. First, with the longer irradiation of incident pulse laser, the higher reflectance contrast of recording mark can be obtained. It indicates that the heat accumulation and structural change on the phase-change $\left(\mathrm{Ge}_{2} \mathrm{Sb}_{2} \mathrm{Te}_{5}\right)$ recording layer. Furthermore, in the irradiation of higher incident pulse power (higher than $10 \mathrm{~mW}$ ), the reflectance contrast is more distinguishable and increases with pulse duration step by step. The step increasing of reflectance contrast means that the structural change and the heat diffusion are not homogeneous on the phase-change recording layer. The multiple stages of reflectance change also provides an advantage in multi-level recording. In the comparison of reflectance contrast on phasechange recording layer with the $\mathrm{ZnO}_{x}$ nanostructured thin film, the contrast is more distinguishable and stable than that on the conventional re-writable recording layer at the same writing power. The reflectance contrast does not show a great difference at long pulse durations, which indicates that there was less structural change and heat accumulation with the $\mathrm{ZnO}_{x}$ nanostructured thin film. However, the highest reflectance contrast can be obtained at short pulse durations. It means that the reflectance contrast can be promoted by the $\mathrm{ZnO}_{x}$ nanostructured thin film without the structural change on phase-change material $\mathrm{Ge}_{2} \mathrm{Sb}_{2} \mathrm{Te}_{5}$.

\section{Conclusion}

In this paper, we use an optical pump-probe system (static media tester, Toptica) to demonstrate the optical response of sandwiched zinc oxide $\left(\mathrm{ZnO}_{x}\right)$ nanostructured thin film, conventional re-writable recording layer, and phase-change recording layer $\left(\mathrm{Ge}_{2} \mathrm{Sb}_{2} \mathrm{Te}_{5}\right)$ with the $\mathrm{ZnO}_{x}$ nanostructured thin film. With the high pulse writing power and the long irradiation on sandwiched $\mathrm{ZnO}_{x}$ nanostructured thin film, the CCD image and low reflectance indicate that sandwiched $\mathrm{ZnO}_{x}$ nanostructured thin film is a highly transparent and thermally stable material. In the $\mathrm{ZnO}_{x}$-type near-field optical disk structure, the contrast and the signals of recording marks can be promoted and are more distinguishable than that on conventional re-writable recording layers. The recording marks can be produced in short pulse duration $(t=50 \mathrm{~ns})$ and tiny bright spots can be produced at the centre of the destroyed hole on the phase-change recording layer with a $\mathrm{ZnO}_{x}$ nanostructured thin film.

\section{Acknowledgements}

We thank the financial supports from National Science Council, Taiwan, R.O.C. under the grand number NSC 95-
2112-M-002-036-MY2 and NSC96-2120-M-002-017, and the Ministry of Economic Affairs of Taiwan, R.O.C. under the grand number 95-EC-17-A-08-S1-0006.

\section{References}

Bagnall, D.M., Chen, Y.F., Zhu, Z., Yao, T., Koyama, S., Shen, M.Y. \& Goto, T. (1997) Optically pumped lasing of $\mathrm{ZnO}$ at room temperature. Appl. Phys. Lett. 70(17), 2230-2232.

Cao, H., Xu, J.Y., Seelig, E.W. \& Chang, R.P.H. (2000) Microlaser made of disordered media. Appl. Phys. Lett. 76(21), 2997-2999.

Cao, H., Xu, J.Y., Zhang, D.Z., et al. (2000) Spatial confinement of laser light in active random media. Phys. Rev. Lett. 84, 5584-5587.

Chu, T.C., Liu, W.C. \& Tsai, D.P. (2005) Enhanced resolution induced by random silver nanoparticles in near-field optical disks. Opt. Commun. 246(4-6), 561-567.

Chu, T.C., Tsai, D.P. \& Liu, W.C. (2007) Readout contrast beyond diffraction limit by a slab of random nanostructures. Opt. Express 15(1), 12-23.

Fu, Y.H., Lu, Y.L., Chang, H.P., Hsu, W.C., Tsai, S.Y. \& Tsai, D.P. (2006) Z-scan study of nonlinear optical coupling of $\mathrm{PtO}_{\mathrm{x}}$ and $\mathrm{Ge}_{2} \mathrm{Sb}_{2} \mathrm{Te}_{2}$ of the near-field optical recording structure. Jpn. J. Appl. Phys. 45(9A), 7224-7227.

Huang, M.H., Mao, S., Feick, H., et al.(2001) Room-temperature ultraviolet nanowire nanolasers. Science 292, 1897-1899.

JCPDS, Joint Committee on Powder Diffraction Standards, file 36-1451.

Kooi, B.J., Groot, W.M.G. \& De Hosson, J.Th.M. (2004) In situ transmission electron microscopy study of the crystallization of $\mathrm{Ge}_{2} \mathrm{Sb}_{2} \mathrm{Te}_{5}$. J. Appl. Phys. 95(3), 924-932.

Lin, S.K., Lin, I.C. \& Tsai, D.P. (2006) Characterization of nano recorded marks at different writing strategies on phase-change recording layer of optical disks. Opt. Express 14, 4452-4458.

Lin, W.C., Kao, T.S., Chang, H.H., et al. (2003) Study of a superresolution optical structure: polycarbonate $/ \mathrm{ZnS}-\mathrm{SiO}_{2} / \mathrm{ZnO} / \mathrm{ZnS}-\mathrm{SiO}_{2}$ $/ \mathrm{Ge}_{2} \mathrm{Sb}_{2} \mathrm{Te}_{5} / \mathrm{ZnS}_{-} \mathrm{SiO}_{2}$. Jpn. J. Appl. Phys. 42, 1029-1030.

Liu, W.C., Wen, C.Y., Chen, K.H., Lin, W.C. \& Tsai, D.P. (2001) Near-field images of the super-resolution near-field structure. Appl. Phys. Lett. 78(6), 685-687.

Miyamoto, M., Hirotsune, A., Miyauchi, Y., Ando, K., Terao, M., Tokusyuku, N.\& Tamura, R. (1998) Analysis of mark-formation process for phase-change media. IEEE J. Quantum Electron. 4, 826-831.

Ohta, T., Nishiuchi, K., Narumi, K., Kitaoka, Y., Ishibashi, H., Yamada, N. \& Kozaki, T. (2000) Overview and the future of phase-change optical disk technology. Jpn. J. Appl. Phys. 39, 770-774.

Pan, Z.W., Dai, Z.R. \& Wang, Z.L. (2001) Nanobelts of semiconducting oxides. Science 291, 1947-1949.

Tsai, D.P. \& Lin, W.C. (2000) Probing the near fields of the super-resolution near-field optical structure. Appl. Phys. Lett. 77(10), 1413-1415.

Tsai, D.P., Yang, C.W., Lin, W.C., et al. (2000) Dynamic aperture of near-field super resolution structures. Jpn. J. Appl. Phys. 39, 982-983.

Wiersma, D. (2000) Laser physics: the smallest random laser. Nature 406, 132-133.

Yu, C.C., Kao, T.S., Lin, W.C., Liu, W.C. \& Tsai, D.P. (2004) Study of optical transmittance of $\mathrm{AgO}_{\mathrm{x}}$ nano thin film in super-resolution near- field structure. J. Scan. Microsc. 26(5), 90-93. 